

ARTIGO ORIGINAL

\title{
A espiritualidade no cuidado perioperatório: a perspectiva do paciente
}

\author{
Spirituality in perioperative care: the patient's perspective \\ La espiritualidad en o cuidado perioperatorio: la perspectiva del paciente
}

Silva, Taline Cristina Vieira da ${ }^{1}$; De Mazzi, Nathália Romeu²

Como citar este artigo: Silva TCV, De Mazzi NR. A espiritualidade no cuidado perioperatório: a perspectiva do paciente. J. nurs. health. 2019;9(2):e199205

\section{RESUMO}

Objetivo: compreender a espiritualidade no cuidado perioperatório sob a perspectiva do paciente. Métodos: pesquisa qualitativa, descritiva e exploratória, realizada por meio de entrevistas semiestruturadas com 10 pacientes em pós-operatório de cirurgia eletiva internados em um hospital paulista entre fevereiro e abril de 2018. Os dados foram submetidos à análise de conteúdo, modalidade temática. Resultados: a espiritualidade foi relacionada às atividades de rotina do paciente, sendo relatada a importância da fé para os enfrentamentos, especialmente na diminuição de angústias no perioperatório. Houve, porém, confusão entre os significados de espiritualidade e religiosidade. Sobre os sistemas de apoio, os entrevistados citaram os líderes religiosos e a família como sustentação à fé no perioperatório, visto que os profissionais de saúde não abordam tal aspecto no cuidado. Considerações finais: há uma dicotomia entre as necessidades dos pacientes e a abordagem da espiritualidade realizada pelos profissionais de saúde, tornando-se necessário repensar os fluxos e protocolos institucionais.

Descritores: Assistência perioperatória; Espiritualidade; Integralidade em saúde; Equipe de assistência ao paciente.

\begin{abstract}
Objective: to understand the spirituality in perioperative care from the perspective of the patient. Methods: a qualitative, descriptive and exploratory study conducted through semi-structured interviews with ten patients in elective surgery postoperatively admitted to a hospital in São Paulo between February and April 2018. The data were submitted to content analysis, thematic modality. Results: spirituality was related to the routine of the patient, and the importance of faith for the confrontations, especially in reduction of anguish in the perioperative period, was reported. However, there was confusion between the meanings of spirituality and religiosity. Regarding the support systems, the interviewees cited religious leaders and the family as faith-supporting during the period, since health professionals do not address this aspect in care. Final considerations: there is a dichotomy between the needs of patients and the approach of spirituality performed by health professionals, making it necessary to rethink institutional flows and protocols.

Descriptors: Perioperative care; Spirituality; Integrality in health; Patient care team.
\end{abstract}

\footnotetext{
1 Discente do curso de Enfermagem. Universidade do Oeste Paulista (UNOESTE). E-mail: talinecristina7@gmail.com http://orcid.org/0000-0001-7662-6331

2 Enfermeira. Mestre em Ensino em Saúde. Universidade do Oeste Paulista (UNOESTE). E-mail: nathaliarmazzi@gmail.com http://orcid.org/0000-0002-8419-9066
} 


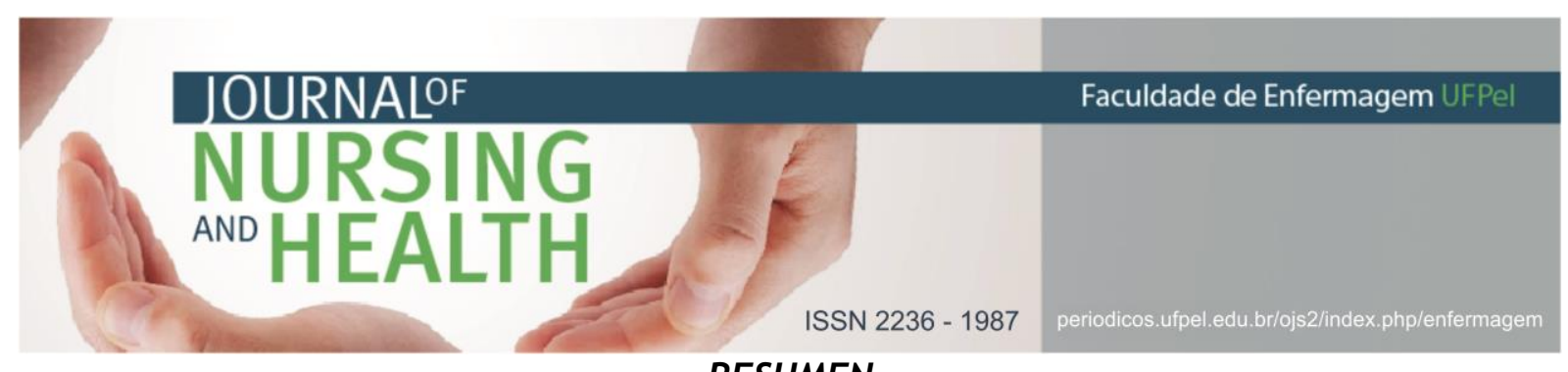

RESUMEN

Objetivo: comprender la espiritualidad en el cuidado perioperatorio bajo perspectiva del paciente. Métodos: investigación cualitativa, descriptiva y exploratoria, realizada por medio de entrevistas semiestructuradas con diez pacientes en postoperatorio de cirugía electiva internados en un hospital de São Paulo, entre febrero y abril de 2018. Los datos fueron sometidos al análisis de contenido, modalidad temática. Resultados: la espiritualidad se relaciona con la rutina del paciente, siendo relatada la importancia de la fe para los enfrentamientos, especialmente con disminución de angustias en el perioperatorio. Hubo confusión entre espiritualidad y religiosidad. Sobre los sistemas de apoyo, los entrevistados citaron a líderes religiosos y familiares como sustentación en el perioperatorio, ya que los profesionales de la salud no abordan tal aspecto en el cuidado. Consideraciones finales: hay una dicotomía entre las necesidades de los pacientes y el enfoque de la espiritualidad realizada por profesionales de salud, haciéndose necesario repensar flujos y protocolos institucionales.

Descriptores: Atención perioperativa; Espiritualidad; Integralidad en salud; Grupo de atención al paciente.

\section{INTRODUÇÃO}

0 cuidado perioperatório corresponde a um período da assistência à saúde hospitalar no qual os profissionais devem acompanhar o paciente de modo singular desde 0 momento em que é tomada a decisão de realizar a intervenção cirúrgica, proporcionando segurança e qualidade da assistência. ${ }^{1-2}$

0 período perioperatório, portanto, compreende três fases, sendo elas: o pré-operatório, período que se inicia 24 horas antes da cirurgia até a entrada do paciente ao centro cirúrgico, sendo que o trabalho da equipe de saúde nesse momento deve estar voltado, tanto para os cuidados pré-operatórios, como para os do intraoperatório. ${ }^{1} \mathrm{O}$ intraoperatório, que é o tempo do paciente na sala cirúrgica, quando ocorre 0 procedimento cirúrgico. E o pós-operatório, que se inicia na sala de recuperação pósanestésica e estende-se até a alta do paciente. ${ }^{1}$

Durante todo esse período, o paciente sente-se apreensivo, pensando sobre 0 procedimento cirúrgico, a anestesia e sua recuperação após a cirurgia, apresentando frequentemente sentimentos de medo e insegurança. Tal situação, portanto, torna o período perioperatório estressante para o paciente, podendo desencadear reações

fisiológicas/psíquicas/sociais/espiritu ais que comprometem sua recuperação. $^{2}$

Nesse sentido, a equipe de saúde tem o papel de atender às demandas do paciente de forma integral, vislumbrando não somente a doença em si ou os cuidados técnicos, mas também assistindo suas aflições, medos e expectativas, partilhando com ele e sua família sobre seu cuidado no intuito de que suas angústias e dúvidas possam ser amenizadas. Esses aspectos talvez sejam aqueles que mais requerem atenção, uma vez que impactam diretamente na relação paciente-profissional e, portanto, na qualidade da assistência. ${ }^{3-4}$

$$
\text { o serviço }
$$

hospitalar, historicamente, realiza cuidados em 


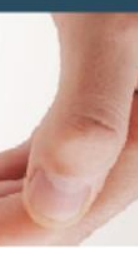

ISSN 2236 - 1987

saúde por meio de ações especializadas e de cunho curativo, dando enfoque à doença. ${ }^{5}$ Todavia, é necessário transformar esse modo de cuidar para uma assistência que seja humanizada e desenvolva a autonomia do paciente, pautada no princípio da integralidade. No período perioperatório essa situação torna-se ainda mais evidente, uma vez que o cuidado é focado predominantemente no procedimento cirúrgico, sendo pouco voltado à singularidade.

Por conseguinte, é importante que a equipe de saúde atenda 0 paciente de modo a centrar o cuidado nas suas expectativas e necessidades, promovendo uma assistência que contemple as dimensões biopsicossociais e espirituais. 0 cuidado como desdobramento da relação entre profissional e paciente não pode atender apenas uma dessas dimensões, já que as questões biológicas, psicológicas e sociais são projetadas na espiritualidade, a qual dá sentido à vida. Incluir a espiritualidade no cuidado perioperatório é considerar o paciente em sua complexidade, almejando um aprimoramento da assistência nesse período, ${ }^{6}$ uma vez comprovado seu impacto positivo no bem-estar pessoal. ${ }^{7}$ Sendo assim, o presente estudo abordará a espiritualidade no cuidado perioperatório.

A espiritualidade pode ser definida como uma característica individual, sendo uma busca pessoal pelo significado e sentido da vida, podendo estar vinculada ou não a uma religião/crença, relacionando-se a algo transcendente. Já a religião é uma prática compartilhada por uma comunidade, que envolve hierarquias, dogmas e presença de líderes a serem seguidos. ${ }^{7}$ A fé, por sua vez, pode estar relacionada tanto à espiritualidade como à religião em si, já que ela se refere ao sentimento de crença em algo maior, subjetivo, que impulsiona a vida. ${ }^{7-8}$

Nos últimos anos têm crescido a procura da cura pela fé, visto a necessidade de integração de corpo, mente e espírito para o alcance de níveis cada vez mais elevados de qualidade de vida. Por isso, é importante que a dimensão espiritual seja considerada no cuidado em saúde, buscando melhores resultados para uma assistência centrada no paciente. ${ }^{8}$ Entretanto, devido às concepções de religião e espiritualidade serem constantemente tratadas como sinônimos e à fragilidade na capacitação de profissionais de saúde para incluir a espiritualidade nas práticas em saúde, tal aspecto ainda é pouco considerado no cuidado. ${ }^{7}$

O papel do profissional, porém, não implica em envolver crenças ou incentivar mudanças de visão, mas em escutar, entender, promover potencialidades e possibilitar um cenário menos adverso para a recuperação do paciente. Isso proporciona fortalecimento, tanto do indivíduo, como da sua família, visto que a espiritualidade está ligada positivamente aos indicadores de bemestar psicológico e, fisiologicamente, diminui o estresse e seus impactos. Assim, o cuidado que considera a espiritualidade deve respeitar a condição do sujeito, livre de preconceitos e tabus. ${ }^{9}$ 


\section{JOURNALOF \\ NURSING \\ AND HEALTH}

ISSN $2236-1987$

A instituição é composta por aproximadamente 2 mil funcionários e possui 550 leitos do Sistema Único de Saúde (SUS), incluindo 56 leitos de Unidade de Terapia Intensiva (UTI). As unidades de internação contam com 460 leitos, divididos em enfermarias cirúrgicas, pediátricas, clínicas, psiquiátricas e ginecologia/obstetrícia. Anualmente, são realizadas em média 20 mil internações. 0 centro cirúrgico, por sua vez, dividido em unidades I, II e Centro obstétrico, realiza procedimentos de pequena, média e alta complexidade, incluindo cirurgias cardíacas, neurológicas e oncológicas. São realizadas por ano, em média, 1.700 cirurgias/mês. ${ }^{11}$

Os participantes do estudo foram 10 pacientes internados nas unidades Cirúrgica Geral, Especialidades I, Especialidades II e Ortopedia do Hospital Regional e submetidos a cirurgias eletivas realizadas entre fevereiro e abril de 2018. Os pacientes foram abordados no período pósoperatório, uma vez que já tinham vivido todas as fases do perioperatório durante a internação. A escolha dos entrevistados foi realizada por conveniência. Foi pactuada com 0 serviço a coleta dos dados uma vez por semana, no período da tarde, pela segunda autora da pesquisa, conforme sua disponibilidade. Acordou-se que a cada semana, a coleta seria realizada em uma das unidades cirúrgicas citadas acima e que, antes da abordagem ao paciente, a pesquisadora teria contato com o enfermeiro da unidade a fim de identificar os pacientes que corresponderiam aos critérios de inclusão e que estariam na unidade no momento. 


\section{JOURNALOF \\ NURSING \\ ANO HEALTH}

Portanto, os critérios de inclusão adotados foram os seguintes: paciente acima de 18 anos, com condições de responder por si mesmo, submetido à cirurgia eletiva. Foram excluídos os pacientes que apresentavam algum tipo de desconforto pós-cirúrgico ou que não estavam na clínica por motivo de procedimentos durante o período de coleta. É importante destacar que nenhum dos pacientes abordados se recusou a participar da entrevista.

Como critério de definição do número de participantes, utilizou-se a saturação teórica, visto que ela se dá quando as informações coletadas se tornam redundantes ou repetitivas, não acrescentando dados relevantes para a coleta, considerando os objetivos propostos para o estudo. A quantidade de respondentes nesse caso não é o aspecto mais importante, porém os dados da coleta devem estar adequados para melhor compreensão e conclusão dos resultados, uma vez que devem ser suficientes para auxiliar na teorização da pesquisa. ${ }^{12}$

A coleta dos dados foi realizada por meio de entrevistas, a partir de um roteiro semiestruturado, entendendo que tal técnica permite investigar sobre um tema livremente, ${ }^{10}$ tomando por base um roteiro com questões norteadoras. Tal roteiro foi elaborado conforme os objetivos da pesquisa, buscando compreender a presença da espiritualidade na vida do paciente e durante o perioperatório, bem como sua abordagem durante a internação, contendo dados de caracterização dos respondentes e as seguintes questões: "Comente sobre a experiência de realizar uma cirurgia", "O que é espiritualidade para você?”, "Como a
ISSN $2236-1987$

espiritualidade está presente no seu dia a dia?", "Como a espiritualidade esteve presente na sua internação para a realização da cirurgia?" e "Comente sobre a abordagem da espiritualidade durante a sua internação". As entrevistas tiveram duração média de 15 minutos, sendo gravadas e transcritas na íntegra.

A análise dos resultados, por sua vez, ocorreu por meio da análise de conteúdo, segundo Minayo, que tem como propósito buscar a compreensão e sentidos dos discursos. Uma narração ou relato sobre determinado assunto ganha significado, contribuindo para 0 desenvolvimento do método e construção da pesquisa. ${ }^{10}$

Existe um amplo campo para aplicação da análise de conteúdo, sendo que na presente pesquisa foi empregada a modalidade temática. Tal modalidade tem como ideia central o tema e consiste em encontrar os núcleos de sentido que emergem dos discursos e podem ter significado para a proposta do estudo, seguindo as etapas de pré-análise, exploração do material e tratamento dos resultados. ${ }^{10}$

Todos os participantes assinaram o Termo de Consentimento Livre e Esclarecido (TCLE) após esclarecimentos sobre os objetivos da entrevista e respeito ao anonimato, sendo identificados por meio da letra "P" de paciente e algarismo arábico, conforme ordem da entrevista, de P1 a P10. Conforme o Parecer 2.478.369 e Certificado de Apresentação para Apreciação Ética (CAAE) número 81217617.8.0000.5515, o presente estudo foi aprovado pelo Comitê de Ética em Pesquisa no ano de 2017. 


\section{RESULTADOS E DISCUSSÃO}

Considerando as características dos participantes, dentre os 10 entrevistados, $80 \%$ eram do sexo feminino, $50 \%$ tinham idade entre 50 e 60 anos, 70\% eram casados e 70\% possuíam ensino fundamental incompleto. Em relação ao tipo de cirurgia, 70\% tinham sido submetidos à cirurgia geral. Sobre religião, $40 \%$ eram católicos, $40 \%$ evangélicos, $10 \%$ testemunhas de Jeová e 10\% espíritas.

A partir da análise das entrevistas foi possível identificar três categorias, sendo elas: "Os significados da espiritualidade e religião", "A dimensão espiritual e o enfrentamento das situações de vida" e "A espiritualidade na internação".

\section{Os significados da espiritualidade e religião}

Com relação à compreensão sobre a espiritualidade, os entrevistados a caracterizaram como a confiança a Deus, relacionada a algo maior, transcendente, e que daria forças à existência.

Espiritualidade é a pessoa acreditar que existe algo. No meu modo de pensar, espiritualidade é quando existe algo além da gente, que te motiva, que te dá força de vontade, que você se apega em algo e para você se concretiza e se realiza naquilo que você quer [...]. Uma coisa abstrata, oculta. É você acreditar no que você não vê. (P3)
A gente pensar em Deus, fazer as coisas que agradem a Deus, servir a Deus. (P4)

Acho que é a gente estar em sintonia com Deus [...]. (P5)

Resultados de estudos semelhantes corroboram os achados da presente pesquisa, pois, assim como nos trechos acima citados, os entrevistados ao falarem sobre espiritualidade também a relacionam com a presença de Deus, desvelada por meio da fé e da confiança para vencer obstáculos. ${ }^{13}$

A espiritualidade pode ser entendida como algo universal e que é inerente ao ser humano, não se restringindo a uma religião, mas cercada de valores pessoais que dão sentido à vida. Carrega consigo o sentido de transcendência, uma vez que está além do visível, relacionando a força que está no indivíduo com algo maior por meio da conexão com outros seres e com o universo. Ela possibilita, portanto, a reflexão das vivências, não sendo necessária uma vinculação às práticas religiosas. ${ }^{14-16}$

Sabe-se que espiritualidade e fé estão relacionadas a uma melhor adesão ao tratamento e busca da melhora da qualidade de vida pelos pacientes. Além disso, também podem contribuir para manter a confiança na equipe de saúde, por isso deve ser explorada e utilizada como ferramenta assistencial para o cuidado centrado no indivíduo. ${ }^{14}$ No perioperatório tal aspecto se torna especialmente relevante devido aos medos e angústias relacionados ao sucesso do procedimento cirúrgico. 


\section{JOURNALOF

Acerca desses significados, o conceito de espiritualidade foi diferenciado do termo religião por um dos participantes.

[...] religião é diferente de fé [...] e a religião são nomes, pessoa religiosa, dados a entidades. Aí as pessoas se apegam a especialidades. (P3)

Caracteriza-se religião como uma atividade realizada de modo coletivo que possui práticas bem definidas, envolvendo rituais alicerçados em uma tradição na tentativa de aproximação com 0 transcendente. 0 ato de executar determinado conjunto de ritos é chamado de religiosidade. ${ }^{14-16}$ Assim, a inserção do indivíduo em determinada religião pode facilitar 0 desenvolvimento do sentimento de pertencer a algo, proporcionando certo acolhimento. ${ }^{15}$

Nas falas dos entrevistados, o termo religião não se desvincula totalmente da espiritualidade, visto que quando indagados sobre 0 seu significado, trouxeram aspectos relacionados à religião, mostrando confusão entre os termos. A religião foi caracterizada por eles como a fé em Deus, conceito similar dado à espiritualidade.

[...] a religião é você acreditar em um Deus maior, um criador. (P6)

É aquela fé que a gente tem no coração para Deus. (P9)

[...] o importante é você estar firmado em uma religião, pois ela nos faz ficar perto de Deus. (P8)
Tal confusão entre os termos fica mais evidente quando a espiritualidade foi caracterizada como algo que pertence às outras religiões que não a católica, sendo a fé associada a uma religião específica. Além disso, foi mencionado que é preciso ser fiel a uma determinada religião.

A religião sim, que a gente tendo fé, que nem eu sou da católica, acredito em Deus. E para mim a religião é importante. Agora já espiritualidade eu não entendo $e$ não tenho vontade de entender, não. (P1)

[...] eu nasci na Católica [religião] e estou na católica, sou batizada. É a que eu conheço e pretendo ficar nela até morrer. (P5)

A religião a gente tem que ser fiel [...]. (P10)

Achados de outras pesquisas apresentam uma diferenciação entre religião e espiritualidade por seus participantes, ${ }^{14-16}$ entretanto no presente estudo essa distinção não se deu de forma clara. O fato de tais termos estarem relacionados ocasiona certa confusão de significados, sendo muitas vezes considerados como sinônimos. Isso porque a discussão da espiritualidade e religiosidade na saúde é relativamente recente, visto a mudança do conceito de saúde e a tentativa de transformação do modelo assistencial biomédico que ainda é muito presente. ${ }^{14-16}$

Portanto, a religião está sempre vinculada à espiritualidade, podendo ser descrita como um gênero da dimensão espiritual. ${ }^{14}$ Tanto a 


\section{ISSN 2236 - 1987}

espiritualidade, como a religiosidade estão relacionadas aos pensamentos positivos para os enfrentamentos diários. ${ }^{15}$ Sendo assim, a assistência no perioperatório deve ser construída juntamente ao paciente, considerando suas perspectivas espirituais, a fim de ampliar e fortalecer suas potencialidades.

\section{A dimensão espiritual e o enfrentamento das situações de vida}

Os participantes destacaram que a espiritualidade está presente em todas as atividades realizadas durante a rotina, mesmo nas pequenas situações, visto que relatam a importância da fé para dar forças nos enfrentamentos diários. Uma das falas relaciona a fé ao catolicismo.

[...] todos os dias quando eu acordo já tenho fôlego de vida e quem me dá esse fôlego de vida é o espírito santo, é Deus, Jesus.

[...] é uma coisa que me dá suporte. Ter fé para mim é saber que eu vou vencer. Ter fé é acreditar no que eu vou realizar. (P3)

[...] está presente em tudo o que eu vou fazer. Eu tenho que estar com o pensamento firme e nunca perder a fé, porque sem fé a gente não é nada. (P5)

\section{[...] tudo o que eu estou fazendo} estou com ela na minha frente, pode ser o que for. [...] tenho muita fé e é a fé que move as coisas. (P7)
Pesquisa realizada com pacientes portadores de doença renal crônica em hemodiálise revelou que a espiritualidade e religiosidade são formas positivas de enfrentamento para as dificuldades da vida diária, uma vez que as pessoas afirmam enfrentar a doença de modo mais positivo, como também seu tratamento. Espiritualidade e religiosidade são relacionadas a apoio e superação em um momento difícil, uma esperança de poder dar um novo sentido à vida, corroborando as falas dos entrevistados no presente estudo. ${ }^{17}$

Da mesma forma, pesquisa realizada com pacientes internados em um centro de terapia intensiva e seus familiares, revelou a espiritualidade como uma forma de enfrentamento de um momento difícil e fortalecimento da esperança. No momento de adoecimento, seja ele qual for, vivencia-se medo e angústias. A espiritualidade estaria relacionada à transformação de tais inquietações em sentimentos de força para encarar e superar a doença, trazendo conforto. ${ }^{18}$

A espiritualidade, portanto, refere-se a uma força ligada ao transcendental, presente de forma individual nos sujeitos, que auxilia a dar significado à realidade vivenciada. Como se trata de um meio para compreensão de si mesmo como ser humano, a espiritualidade transmite a quem sofre esperança para lidar com o processo de saúde e enfrentá-lo com mais consciência. ${ }^{7}$

Nesse sentido, os participantes discorreram sobre a forte relação entre a espiritualidade e o momento perioperatório, visto que antes mesmo 
de serem questionados sobre a vivência atual relacionada ao processo cirúrgico já citaram a fé para o enfrentamento da internação.

A noite estava bem insegura, mas aí eu fui pedindo para Deus, para Nossa Senhora Aparecida. No dia eu estava tranquila, bem tranquila. (P1)

[...] eu fiquei muito chocado, porque eu perdi um dedo nessa cirurgia e é nessa hora que a gente tem que ter um espírito de fé $[\ldots]$. ( $\mathrm{P} 2)$

[...] a experiência do pósoperatório é triste. [...] As dores, as medicações, as furadas, mas o importante é a gente sarar e foi um sucesso minha cirurgia, graças a Deus. (P3)

Por isso, quando questionados sobre a relação entre a internação atual, objetivando 0 tratamento cirúrgico, e a espiritualidade, os participantes afirmaram que a fé deu suporte e segurança para o enfrentamento da assistência perioperatória, especialmente no que diz respeito ao procedimento cirúrgico em si, diminuindo angústias e medos.

Eu não senti medo nenhum, então foi através da fé. [...] foi o que me fortaleceu e me apoiou em tudo. (P1)

[...] acaba dando suporte para que você realize com segurança, passa uma segurança para você. (P3)

Os aspectos espirituais mantêm relação direta com sintomas
ISSN 2236 - 1987

psicossomáticos que envolvem as doenças e/ou procedimentos cirúrgicos. Nesse caso, a cirurgia representa uma ameaça ao bem-estar do paciente e a espiritualidade impacta de forma positiva nos sintomas de angústia, ansiedade, depressão e, até mesmo, na dor crônica. ${ }^{7}$

No caso da dor, a espiritualidade e a religiosidade podem ser caracterizadas como ferramentas essenciais utilizadas para seu alívio e enfrentamento, auxiliando na diminuição da percepção dolorosa por meio da ativação do hipotálamo, glândula pituitária e adrenal, liberando mediadores químicos, como serotonina, no sistema nervoso central. No caso do estresse, as práticas espirituais de meditação e oração podem reduzir células imunes envolvidas nesse processo, diminuindo seus impactos negativos. Por isso, é importante que o cuidado em saúde seja planejado a fim de permitir tais práticas nos cotidianos dos serviços, visto que são de baixo custo e de simples organização. ${ }^{19-20}$

Os participantes citaram ainda o pedido de auxílio espiritual para a equipe médica responsável pela cirurgia, uma vez que para eles o sucesso do procedimento foi possível com o apoio de Deus. O sentimento de tranquilidade no transoperatório também foi relacionado à dimensão espiritual e religiosa.

\section{[...] pedi bastante a Deus que} fosse tudo bem, que Deus abençoasse os médicos que iriam cuidar de mim na cirurgia. (P4) 


\section{,}

Deus foi bom: Ele entrou na frente e os médicos conseguiram. (P7)

[...] porque Deus deixou os médicos para nos ajudar nessa parte da medicina e está nos ajudando. Na bíblia fala que Lucas [apóstolo de Jesus] era médico. (P8)

Quando eu fui para o centro cirúrgico eu pedi para Deus estar lá junto com os médicos. (P10)

Depois que eu fui para sala de cirurgia, graças a Deus, eu já coloquei Deus na frente, os anjos junto, Jesus [...] e foi tranquilo. (P6)

Estudo que envolveu pacientes com insuficiência cardíaca verificou que a espiritualidade e religião são associadas à qualidade de vida global, apresentando relação direta, portanto, com o processo de saúde e doença. 0 estudo revelou ainda que existe uma favorável e significativa associação entre espiritualidade e religião na qualidade de vida dos pacientes, proporcionando maior bem-estar mental e emocional. ${ }^{21}$ Nessa perspectiva, os resultados encontrados na presente pesquisa vão ao encontro desses estudos, uma vez que os entrevistados afirmam sentir o impacto positivo da espiritualidade em seu tratamento, mesmo que empiricamente. Por isso, torna-se necessário o investimento na abordagem da espiritualidade no perioperatório, objetivando melhores condições clínicas e psicossociais aos pacientes. É importante, por conseguinte, repensar o processo de
ISSN $2236-1987$

trabalho nesse período, bem como refletir e modificar os fluxos e protocolos institucionais, buscando atender a essa demanda na prática clínica hospitalar.

\section{A espiritualidade na internação}

Em relação à abordagem da espiritualidade durante a hospitalização, os participantes referiram que os profissionais de saúde não mencionaram o tema dentro do cuidado em nenhum dos momentos do perioperatório. Entretanto, citaram o carinho recebido pela equipe de enfermagem, relatando ainda que tais profissionais poderiam abordar a espiritualidade durante a internação, porém não o fazem devido ao excesso de atividades.

Não, ninguém falou comigo sobre isso. A primeira foi você. (P4)

Não, ninguém me abordou sobre esse assunto. [...] as enfermeiras são pessoas muito boas, [...] com muito carinho com o paciente. [...] elas não falam sobre isso, poderiam falar. Acho que não sabem, [...] mas também é muita coisa para elas fazerem. (P2)

Estudos apontam que os pacientes desejam receber suporte espiritual durante a assistência em saúde, ${ }^{22-23}$ assim como citam os participantes da presente pesquisa. Os respondentes ainda relacionam bons sentimentos e experiências positivas vividas durante $\mathrm{o}$ perioperatório à equipe de enfermagem, porém tais profissionais ainda não contemplam a espiritualidade no cuidado prestado, como é de desejo dos entrevistados. 
Em contrapartida, alguns pacientes também citaram que a fé é um aspecto individual para ser abordado pelos profissionais de saúde, que cada indivíduo deve ter sua fé de modo particular.

[...] eles nem podem comentar com a gente, porque esse negócio da fé tem que ser eles mesmos, eles pedirem para Deus [...]. (P7)

Não, a fé eu já trouxe de casa. (P9)

Os conceitos de espiritualidade e religiosidade ainda causam confusão entre os pacientes, o que também pode acontecer com os profissionais de saúde. Talvez seja por esse motivo que o tema ainda seja pouco abordado no planejamento do cuidado, visto que os trabalhadores da saúde ainda vivenciam o medo das repercussões da abordagem de aspectos espirituais durante o cotidiano dos serviços, temendo confundi-los com suas próprias crenças e escolha religiosa, mesmo considerando importante a espiritualidade para o tratamento do paciente. Motivos adicionais relacionados à discreta abordagem da espiritualidade na prática em saúde são o pouco preparo dos profissionais para sua contextualização na prática clínica e a predominância do modelo biomédico nos serviços. ${ }^{23-25}$

O profissional de saúde, acima de tudo, deve proporcionar ao paciente as melhores formas de enfrentar o processo de saúde e doença durante a internação, centrando a assistência em suas necessidades, sejam elas explícitas por meio da comunicação ou implícitas, o que inclui a dimensão espiritual como uma das facetas da
ISSN 2236 - 1987

assistência integral. Sendo assim, a espiritualidade possui relação direta com a construção de vínculo entre paciente e profissional, necessária para a qualidade da assistência. ${ }^{24}$

Com relação à abordagem da espiritualidade, por sua vez, é importante que os profissionais de saúde não aprofundem esse aspecto logo no início do contato com o paciente, mas após o estabelecimento de algum vínculo, sempre de forma respeitosa e sensível, aproveitando algum momento no qual haja indícios da relevância da espiritualidade na vida do indivíduo. Por vezes também não é apropriado o profissional divulgar suas opiniões ao paciente, todavia se isso for solicitado é necessário usar o julgamento clínico ao compartilhar suas visões, pois tal fato pode tornar o paciente mais confortável a compartilhar suas experiências. ${ }^{23}$

Isso significa que a abordagem dos profissionais de saúde sobre tais aspectos no cuidado perioperatório deve ser cautelosa e voltada à espiritualidade, e não à religiosidade, visto a sua especificidade sociocultural. A investigação da espiritualidade, durante 0 contato profissional-paciente, deve ocorrer, com 0 intuito de entender a importância dessa dimensão para a recuperação e subsidiar o enfrentamento do momento vivido. ${ }^{23}$ Com essa compreensão, se houver necessidade e vontade do paciente, as demandas religiosas específicas podem ser trabalhadas juntamente aos respectivos líderes e/ou instituições de preferência de cada indivíduo.

Mesmo o local de estudo sendo coordenado por uma associação 


\section{JOURNALOF

religiosa, os participantes não mencionaram apoio espiritual da equipe de saúde durante a internação. Por isso, citaram que a abordagem da espiritualidade e, principalmente da religião, ocorreu de forma pontual por meio de acompanhantes, folders disponíveis na recepção do hospital, líderes religiosos e familiares.

Meu marido foi lá fora e trouxe um livrinho sobre a bíblia. [...] veio o marido da moça que está ali também. Ele é evangélico $e$ fez uma oração só (P6)

A única que falou foi você e o meu pastor que veio me visitar. (P10)

Quando internei vieram os evangélicos. Vem a madre de vez em quando. Eles falam muito de Deus, sobre Espírito Santo. Para mim foi muito bom, porque a gente nunca está sozinho. [...] eles vêm e só dão uma força. [...] na hora a gente se apega com Deus, Espírito Santo, $e$ os parentes da gente falam: 'não, você vai na fé que nós vamos orar por ti'. (P2)

É primordial que haja investimento em espaços de discussão sobre a temática em todo o processo de formação profissional, principalmente no que tange à educação permanente, momento no qual os profissionais já estariam um pouco mais amadurecidos frente às experiências já vivenciadas na prática assistencial. ${ }^{24}$ Sendo a espiritualidade, portanto, inerente ao ser humano, torna-se necessário que as ações de promoção espiritual não estejam limitadas apenas às orações e leituras promovidas por líderes religiosos que atuam no cenário hospitalar, assim como citado pelos entrevistados desta pesquisa. Os profissionais de saúde devem incluir tal aspecto na sua prática, visto seu impacto positivo para o cuidado e o serviço.

\section{CONSIDERAÇÕES FINAIS}

A espiritualidade no presente estudo esteve relacionada a algo transcendente que dá força para o enfrentamento das situações de vida, sendo citada como aspecto importante durante o período perioperatório, diminuindo a angústia e o medo, embora tenha sido muito confundida com o conceito de religião. Em relação a sua abordagem, mesmo a espiritualidade não sendo mencionada pelos profissionais durante o cuidado, os participantes relataram o apoio de líderes religiosos e familiares durante a internação.

Frente à necessária abordagem dos aspectos espirituais reconhecidos por proporcionar força, tranquilidade e bem-estar aos pacientes no período perioperatório, compreende-se que ainda há uma dicotomia entre essas necessidades e a prática realizada pelos profissionais de saúde sobre o tema durante a assistência prestada, mesmo em instituições que possuam organização de cunho religioso, como é o caso do cenário desta pesquisa.

Por isso, compreender a percepção do paciente sobre a espiritualidade no cuidado cirúrgico tem a potencialidade de contribuir para uma assistência perioperatória centrada no usuário, considerando suas necessidades e expectativas, e 


\section{NURSING \\ AND}

ISSN 2236 - 1987

3 Viegas SMF, Penna, CMM. As dimensões da integralidade no cuidado em saúde no cotidiano da estratégia de saúde da família no vale do Jequitinhonha, MG, Brasil. Interface comun. saúde educ. [Internet]. 2015[acesso em 2019 mar 06];19(55):1089-100. Disponível em: http://www.scielo.br/pdf/icse/v19n5 5/1807-5762-icse-1807576220140275.pdf

4 Garret HJ. Effective perioperative communication to enhance patient care. AORN J [Internet]. 2016[cited 2019 Mar 06];104(2):111-20. Available from:

https: / /aornjournal.onlinelibrary. wile y.com/doi/epdf/10.1016/j.aorn.2016. 06.001

5 Wanderbroocke ACNS, Baasch C, Antunes MC, Menezes M. O sentido de comunidade em uma equipe multiprofissional hospitalar: hierarquia, individualismo, conflito [Internet]. Trab. educ. saúde. 2018[acesso em 2019 abr 22];16(3):1157-76. Disponível em: http: / /www.scielo.br/pdf/tes/v16n3/ 1678-1007-tes-1981-7746-sol00155.pdf

6 Marakami R, Campos CJG. Religião e saúde mental: desafio de integrar a religiosidade ao cuidado com 0 paciente. Rev. bras. enferm. [Internet]. 2012[acesso em 2019 mar 06];65(2):361-67. Disponível em: http://www.scielo.br/pdf/reben/v65 n2/v65n2a24.pdf

7 Evangelista CB, Lopes MEL, Costa SFG, Batista PSS, Batista JBV, Oliveira AMM. Palliative care and spirituality: an integrative literature review. Rev. bras. enferm. [Internet]. 2016[cited 2019 Mar 06];69(3):554-63. Available 0397.pdf 


\section{JOURNALOF \\ NURSING

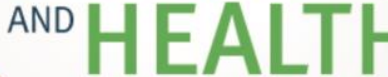

from:

http: / /www.scielo.br/pdf/reben/v69 n3/en_0034-7167-reben-69-030591.pdf

8 Silva MCM, Moreira-Almeida A, Castro EAB. Idosos cuidando de idosos: a espiritualidade como alívio das tensões. Rev. bras. enferm. [Internet]. 2018[acesso em abr 23];71(5):2461-8. Disponível em: http: / /www.scielo.br/pdf/reben/v71 n5/pt_0034-7167-reben-71-05-

2461.pdf

9 Oliveira GR, Fittipaldi Neto J, Salvi MC, Camargo SM, Evangelista JL, Espinha DCM, et al. Saúde, espiritualidade e ética: a percepção dos pacientes e a integralidade do cuidado. Rev. Soc. Bras. Clín. Méd. [Internet]. 2013[acesso em 2019 mar 06];11(2):140-14. Disponível em: http://files.bvs.br/upload/S/1679-

1010/2013/v11n2/a3566.pdf

10 Minayo MCS, Deslandes SF, Gomes R. Pesquisa social: teoria, método e criatividade. Petrópolis: Vozes; 2016.

11 Hospital Regional de Presidente Prudente (HRPP). Quem somos [Internet]. 2019[acesso em 2019 mar 06]. Disponível em: http:/ / www.hrpresidenteprudente.or g.br/pagina. aspx?id=114

12 Nascimento LCN, Souza TV, Oliveira ICS, Moraes JRMM, Aguiar RCB, Silva LF. Theoretical saturation in qualitative research: an experience report in interview with schoolchildren. Rev. bras. enferm. [Internet]. 2018[cited 2019 Mar 06];71(1):228-33. Available from: http://www.scielo.br/pdf/reben/v71 n1/0034-7167-reben-71-01-0228.pdf
ISSN 2236 - 1987

13 Arrieira ICO, Thoferhn MB, Schaefer OM, Fonseca AD, Kantorski LP, Cardoso $\mathrm{DH}$. The sense of spiritual care in the integrality of attention in palliative care. Rev. gaúch. enferm. [Internet]. 2017[cited 2019 Mar 06];38(3):e58737. Available from: http: //www.scielo.br/pdf/rgenf/v38n 3/en_0102-6933-rgenf-38-3e58737.pdf

14 Benites AC, Neme CMB, Santos MA. Significados da espiritualidade para pacientes com câncer em cuidados paliativos. Estud. Psicol. (Campinas, Online). [Internet]. 2017[acesso em 2019 mar 06];34(2):269-79. Disponível em:

http:/ / www.scielo.br/pdf/estpsi/v34 n2/0103-166X-estpsi-34-02-00269.pdf

15 Chaves LJ, Gil CA. Older people's concepts of spirituality, related to aging and quality of life. Ciênc. Saúde Colet. [Internet]. 2015[cited 2019 Mar 06];20(12): 3641-52. Available from: http://www.scielo.br/pdf/csc/v20n12 /en_1413-8123-csc-20-12-3641.pdf

16 Penha RM, Silva MJP. Meaning of spirituality for critical care nursing. Texto \& contexto enferm. [Internet]. 2012[cited 2019 Mar 06];21(2):260-8. Available from: http://www.scielo.br/pdf/tce/v21n2/ en_a02v21n2.pdf

17 Leimig $M B C$, Lira RT, Peres FB, Ferreira AGC, Falbo AR. Qualidade de vida, espiritualidade, religiosidade e esperança em pessoas com doença renal crônica em hemodiálise. Rev. Soc. Bras. Clín. Méd. [Internet]. 2018[acesso em 2019 mar 06];16(1):306 Disponível em: http: / / docs.bvsalud.org/biblioref/201 8/06/884990/dezesseis_trinta.pdf. 
18 Vale CCSO, Líbero ACA. A espiritualidade que habita o CTI. Mental. [Internet]. 2017[acesso em 2019 mar 06];11(21):321-38. Disponível em:

http://pepsic. bvsalud.org/pdf/mental /v11n21/v11n21a03.pdf

19 Gaudette H, Jankowski KRB. Spiritual coping and anxiety in palliative care patients: a pilot study. J Health Care Chaplain [Internet]. 2013[cited 2019 Mai 03];19(4):131-9. Available from: https://www.tandfonline.com/doi/ful l/10.1080/08854726.2013.823785

\section{Lago-Rizzardi CD, Teixeira MJ,} Siqueira SRDT. Espiritualidade e religiosidade no enfrentamento da dor. Mundo saúde (Impr.). [Internet]. 2010[acesso em 2019 mar 06];34(4):483-7. Disponível em: http://www.saocamilo-

sp.br/pdf/mundo_saude/79/483e487. pdf

21 Abu HO, Ulbricht C, Ding E, Allison JJ, Salmoirago-Blotcher E, Goldberg RJ, et al. Association of religiosity and spirituality with quality of life in patients with cardiovascular disease: a systematic review. Qual Life Res [Internet]. 2018[cited 2019 Mar 06];27(11):2777-97. Available from: https://www.ncbi.nlm.nih.gov/pmc/a rticles/PMC6196107/pdf/11136_2018_ Article_1906.pdf

22 Oliveira RM, Santos RMM, Yarid SD. Spirituality/religiosity and humanizasus in family health units. Revista Brasileira em promoçao da saude (Online) [Internet]. 2018[cited 2019 Mar 06]; 31(1):1-8. Available from:
https://periodicos.unifor.br/RBPS/art icle/view/6524/pdf_1

23 Moreira-Almeida A, Koenig HG, Luccheti G. Clinical implications of spirituality to mental helath: review of evidence and pratical guidelines. Rev. bras. psiquiatr. [Internet]. 2014[cited 2019 Mar 06];36:176-182. Available from:

http://www.scielo.br/pdf/rbp/v36n2 /1516-4446-rbp-2014-36-2-176.pdf

24 Tavares MM, Gomes AMT, Barbosa DJ, Rocha JCC, Bernardes MMR, Thiengo PCS. Spirituality and religiosity in the daily routine of hospital nursing. Rev. enferm. UFPE on line. [Internet]. 2018[cited 2019 Mar 06];12(4):1097-102. Available from: https://periodicos.ufpe.br/revistas/r evistaenfermagem/article/view/2347 $80 / 28687$

25 Siqueira HCH, Cecagno D, Medeiros $A C$, Sampaio AD, Rangel RF. Spirituality in the health-illness-care of the oncological user process: nurse's outlook. Rev. enferm. UFPE on line. [Internet]. 2017[cited 2019 Mar 06];11(8):2996-3004. Available from: https://periodicos.ufpe.br/revistas/r evistaenfermagem/article/view/1102 02/22098

Data de submissão: 17/12/2018

Data de aceite: 27/04/2019

Data de publicação: 09/05/2019 